\title{
Insights into the recovery if the palila (Loxioides bailleui) on hawaii through use of systems behavior charts
}

\begin{abstract}
Conservation management requires decisions, interventions and goal-setting that will enable recovery of vulnerable species populations and habitats. System Behavior Charts involve analysis of longitudinal data sets to identify changes over time and to predict future status of the system. The insights they provide can offer insights for decision-making or action and therefore useful for management of species recovery programmes. The Palila (Loxioides bailleui) is a Hawaiian honeycreeper which is currently in decline. This study presents an analysis of population counts of Palila since 1980 using the Systems Behaviour Chart methodology. The results of the analysis reveal that despite population counts for Palila decreasing since 2003, the bird's population has now stabilized and less precarious situation than the apparently larger pre-2003 population. Conservation managers can investigate why the population has stabilised and how that insight can be used to replicate future growth of the population towards sustainable recovered population.
\end{abstract}

Keywords: conservation, hawaii, statistical process control, population, honeycreeper, decision-making
Volume 2 Issue I - 2017

\author{
Akshita V Pungaliya, Simon A Black \\ Durrell Institute for Conservation and Ecology, University of \\ Kent, UK
}

Correspondence: Simon A. Black, Durrell Institute for Conservation and Ecology, Marlowe Building, University of Kent, Canterbury, Kent, United Kingdom, Email s.black@kent.ac.uk

Received: April 04, 2017 | Published: April 24, 2017

\section{Introduction}

The Hawaiian archipelago is one of the most isolated groups of islands in the world with a diverse flora and fauna with high percentage of endemism. ${ }^{1,2}$ The ecosystem on the Hawaiian Islands began facing challenges 1200 years ago when Polynesian settlers brought rats, pigs and $\operatorname{dogs}^{2}$ followed in the late 1700's, by Europeans bringing rats, cattle, sheep, goat, cats, pigs and other disease vectors including mosquitos. Hawaii has lost more than half of its endemic birds. ${ }^{3,4}$ Despite the real challenges of introduced species and diseases, the prime reason for continued declines in bird species is believed to be the lack of implementation of management actions at relevant scales. ${ }^{4}$ This case study presents how the use of Systems Behaviour Charts to understand longitudinal population data can provide helpful insights into bird population management. System Behaviour Charts represent data variations over the passage of time., We present the case of Palila (Loxioides bailleui), a Hawaiian honeycreeper which is currently facing population decline.

\section{Case presentation}

Population counts for Palila were collated from previously established data in historical records, population surveys, field notes and unpublished notes. Fortunately with System Behaviour Charts as few as twenty data points provide useful insight. ${ }^{6}$ Population survey counts for wild Palila from 1980 to $2016^{7}$ were plotted on a chart (Figure 1) alongside calculated Natural Limits. The mean $(\overline{\mathrm{x}})$ of the population count data was plotted as the central line and the standard deviation $(\sigma)$ was further used to calculate four control limit lines: ${ }^{6}$ Centre Line $=\overline{\mathrm{X}}$; Upper Natural Limit: $\mathrm{UNL}=\overline{\mathrm{X}}+3 \sigma$; Lower Natural Limit: $\mathrm{LNL}=\overline{\mathrm{x}}-3 \sigma$; Upper Warning Limit: $\mathrm{UNL}=\overline{\mathrm{x}}+2 \sigma$; Lower Warning Limit: $L W L=\bar{x}-2 \sigma$. The position of data points relative to these empiricallyderived limit lines enables differentiation of routine variations from exceptions. ${ }^{6}$ These data-derived observations stimulate investigation of potential factors for taking action, making decisions or setting goals. This is an important feature which is not considered in other superficially similar approaches such as the 'decision trigger' idea, ${ }^{8}$ where arbitrary assumptions of 'desirable' and 'undesirable' performance are accepted. The Systems Behaviour Chart of population counts for Palila reveals that from 1980 to 2003 counts remain within natural limits (Figure 1). However, the lower natural limit for the run of data from 1980 is negative, indicating that the species position is critical. From a probability viewpoint it could possibly become extinct in any future year; a zero count is no more unexpected than any count up to the Upper Natural Limit. From 2003 a sharp, decline in the data shows the population system is statistically 'out of control'. ${ }^{6}$ Since it is a continuous uncontrolled decline, limits are not recalculated until the next stable system which appears from 2010 to 2016, where the limits are recalculated. In contrast to wide and negative natural limits prior to 2003, the second system shows limits which lie closer to the new mean and are also greater than zero.

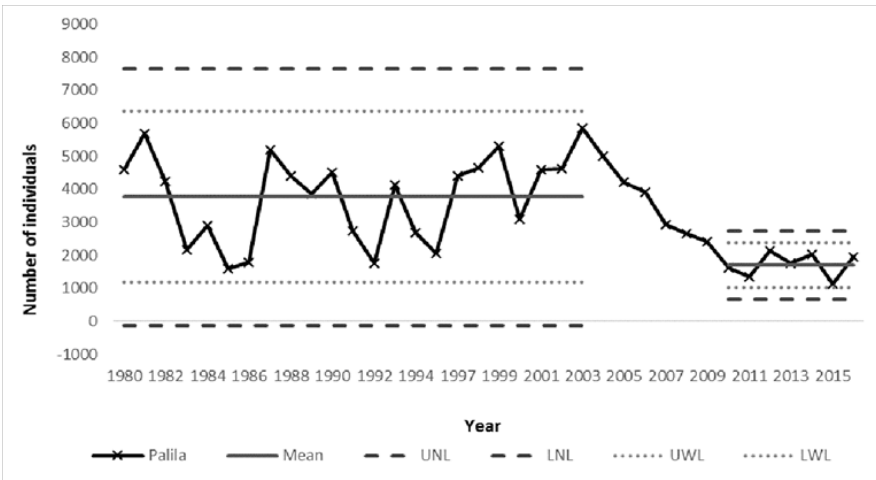

Figure I Population estimates of Palila (Loxioides bailleui) on Hawaii from 1980 to 2015 (Camp, Brinck \& Banko 7 Mean, natural and warning limits are calculated for 1980-2003(left) and 2010 to 2016 (right). 


\section{Discussion}

The Palila has faced decline, but despite the absolute population counts being lower than before 2003, the Systems Behaviour Chart reveals that the situation actually improved after 2011. This is indicated by the reduction in variation in the data across 2011-2016, with the likelihood of the population being maintained in future being shown by the LNL being above zero. This tightening of natural limits, despite decline in absolute numbers of birds, could be due to birds consolidating in favourable areas after habitat loss, causing range contraction. ${ }^{2}$ Fundamental improvement in the LNL is likely due to removal of ungulates and forest rehabilitation. ${ }^{3}$

The Palila population is stable but not fully recovered, which directs decisions towards replication of habitat conditions (e.g. removal of invasive species and habitat restoration) before captive breeding and release. Resources are scarce in conservation and prioritization involves complex decision-making in the face of numerous challenges. ${ }^{9}$ The failure to act quickly can lead to extinctions. ${ }^{10}$ It is critical to be watchful for changes in data point positions relative to SBC limits, if established statistical rules indicate that the system is out of statistical control. ${ }^{6}$ The advantage of the SBC is that the impact of an intervention can be quickly assessed relative to previous data using the same analytical rules. ${ }^{9,11}$

\section{Acknowledgements}

The authors acknowledge the support of S.C. Leslie in advising on analysis for this research, and the uggestions of J. Groombridge, G. Rodda for accessing historical reference materials and data sources and D. Roberts for providing feedback on an earlier version of the manuscript.

\section{Conflict of interest}

The author declares no conflict of interest.

\section{References}

1. Atkinson CT, LaPointe DA. Introduced avian diseases, climate change, and the future of Hawaiian honeycreepers. J Avian Med Surg. 2009;23(1):53-63

2. Scott JM, Mountainspring S, Ramsey FL, et al. Forest bird communities of the Hawaiian Islands: their dynamics, ecology, and conservation. Studies in Avian Biology (9), Cooper ornithological society. Kansas: Allen Press; 1986.

3. Scott JM, Conant S, Van Riper C. Evolution, Ecology, Conservation and Management of Hawaiian Birds. Studies in Avian Biology (22), Cooper ornithological society. Kansas: Allen Press; 2001.

4. Pratt TK. Conservation Biology of Hawaiian Forest Birds: Implications for Island Avifauna. London: Yale University Press; 2009.

5. Shewhart WA. Economic control of quality of manufactured product. USA: ASQ Quality Press; 1931.

6. Black SA. System Behavior Charts inform an understanding of biodiversity recovery. International Journal of Ecology. 2015;2015:6.

7. Camp RJ, Brinck KW, Banko PC. 2015-2016 Palila abundance estimates HCSU-TR. 2016;76

8. Addison PF E, Cook CN, de Bie K. Conservation practitioners' perspectives on decision triggers for evidence-based management. Journal of Applied Ecology. 2016;53:1351-1357.

9. Black SA, Groombridge JJ, Jones CG. Leadership and conservation effectiveness: finding a better way to lead. Conservation Letters. 2011;4:329-339.

10. Martin TG. Acting fast helps avoid extinction. Conservation Letters. 2012;5(4):274-280.

11. Cook CN, Mascia MB, Schwartz MW, et al. Achieving conservation science that bridges the knowledge-action boundary. Conservation Biology. 2013;27(4):669-678. 